\title{
Het procedurele mijnenveld van het ontslag op staande voet
}

\author{
F.G. Lagland
}

\section{Het onderwerp}

Het afscheid van Cees Loonstra en Corjo Jansen valt een paar maanden na de inwerkingtreding van de tweede tranche van de Wet werk en zekerheid (Wwz): de wijziging van het ontslagrecht. Het ontslagrecht was de afgelopen vijftien jaar een geliefd onderwerp voor een bijdrage in ArA van de een, de ander of hen samen. Al die jaren werd in de politiek gesproken over een wijziging van het ontslagrecht en verschillende voorstellen passeerden de revue. Over deze voorstellen hebben de heren zich naar mijn weten nooit op schrift uitgelaten. Bij ArA geldt het adagium 'zolang een wet nog niet is aangenomen, wordt er niet over geschreven'. Waar richtten de heren zich dan wel op in hun artikelen en annotaties over het ontslagrecht? Zij zoomden onder meer in op samenloopperikelen. Zo schreven ze over de verhouding tussen een contractuele vergoeding en de ontbindings- en/of kennelijk onredelijk ontslagprocedure en de werking van de redelijkheid en billijkheid bij een beëindiging van de arbeidsovereenkomst. Over de samenloopperikelen onder de Wwz hadden de heren zich vanaf 1 juli 2015 in ArA kunnen (beter gezegd: mogen) uitlaten. Dat gaat spijtig genoeg niet gebeuren. Het verlaten van de redactie betekent ook dat Cees Loonstra en Corjo Jansen hun - vaak toch wel jaarlijkse - bijdragen aan ArA zullen staken. Aan de volgende generatie de taak het stokje over te nemen. Met dit artikel zet ik daartoe een eerste stap. Ik bekijk hoe het ontslag op staande voet in zijn nieuwe vorm processueel uitpakt. Meer concreet ga ik na wat de noodzaak tot vernietiging in rechte betekent voor het kort geding en de (voorwaardelijke) ontbindingsprocedure. De focus van deze bijdrage ligt op de procedurele samenloopperikelen; materiële aspecten komen slechts zijdelings aan bod.

\section{Het kort geding}

\subsection{Bestaansrecht: spoedeisend belang?}

Ondanks kritiek van de Vereniging Arbeidsrecht Advocaten Nederland (VAAN) is vanaf 1 juli 2015 de vernietiging van het ontslag op staande voet nog slechts mogelijk in rechte (artikel 7:681 lid 1 onder a Burgerlijk Wetboek (BW)). In de visie van de minister is op goede gronden afgezien van de buitengerechtelijke vernietiging om redenen van vereenvoudiging en versnelling van het ontslagrecht. ${ }^{1}$ De versnelling is erin gelegen dat de werknemer die de opzegging wenst te vernietigen daartoe binnen twee maanden een verzoek moet indienen bij de rechter. 
Stuiting is niet mogelijk; de tweemaandentermijn is een vervaltermijn (artikel 7:686a lid 4 onder a BW). De tweemaandentermijn is aanzienlijk korter dan de zes maanden die de werknemer voorheen had op grond van artikel 9 van het Besluit Bijzondere Arbeidsverhoudingen (BBA). Slechts onder zeer strikte omstandigheden zal - naar ik verwacht - afwijking zijn toegestaan. Ik put hiervoor inspiratie uit het onder meer door Corjo Jansen geannoteerde ABN AMROarrest van 22 juni 2012. ${ }^{2}$ De Hoge Raad overwoog dat de redelijkheid en billijkheid meebrachten dat een geestelijk gestoorde werknemer niet aan de verjaringstermijn van artikel 9 BBA kon worden gehouden. Een analoge toepassing op de huidige vervaltermijn van twee maanden ligt in de rede. ${ }^{3}$

Vernietiging kan niet in kort geding. De werknemer vordert als voorlopige voorziening loon en tewerkstelling. Vóór 1 juli 2015 was het starten van een bodemprocedure niet vereist. De vernietiging kon buitengerechtelijk plaatsvinden. Partijen konden zich daarom neerleggen bij de uitkomst van het kort geding en deden dat in de praktijk ook vaak. Dat is na 1 juli 2015 anders. De werknemer is thans gehouden binnen twee maanden na het ontslag op staande voet een bodemprocedure te starten waarin hij vernietiging van de opzegging verzoekt. Bestaat gezien deze wijziging een functie voor het kort geding? Met andere woorden: heeft de werknemer nog wel een spoedeisend belang bij zijn vorderingen tot loon en tewerkstelling?

Artikel 7:686a lid 5 BW regelt dat de kantonrechter het verzoek tot vernietiging binnen vier weken na indiening in behandeling neemt. Dat is relatief snel. Aan de andere kant bepaalt de tekst niets over de termijn waarop de kantonrechter beschikking moet wijzen. Ook het procesreglement verzoekschriftprocedures noemt geen harde termijnen. Hoewel de doorlooptijd van een verzoekschriftprocedure doorgaans sneller is dan die van een dagvaardingsprocedure, moet uit deze wijziging niet te veel hoop op een snelle behandeling worden geput. Het gaat nog steeds om een geschil tussen twee partijen waarop naar mijn inschatting het bewijsrecht vol van toepassing zal zijn. ${ }^{4}$ Een vergelijking met de ontbindingsprocedure - waar het bewijsrecht niet altijd integraal van toepassing is - gaat niet op. De ontbindingsprocedure is een in de wet geregelde, eenvoudige, op een spoedige beslissing gerichte verzoekschriftprocedure, ${ }^{5}$ terwijl een ontslag op staande voet vaak lastige zaken betreft. Bovendien zijn de consequenties voor de werknemer zeer ingrijpend van aard. De werknemer staat per direct zonder enige vergoeding op straat en heeft evenmin recht op een werkloosheidsuitkering. Ook volgens de

2 C.J.H. Jansen \& J.E. Jansen, Derogerende werking van de redelijkheid en billijkheid in het arbeidsrecht, ArA 2013/1.

3 In gelijke zin S.F. Sagel, Het ontslag op staande voet en de WWZ (II), TRA 2015/56. Sagel sluit daarnaast niet uit dat de werkgever op grond van artikel 7:611 BW gehouden is de werknemer die op staande voet is ontslagen erop te wijzen dat hij daartegen binnen twee maanden bij de rechter kan opkomen.

4 Vgl. P.J. Jansen, Ontslag op staande voet en de Wet werk en zekerheid: is er nog plaats voor het kort geding, voorwaardelijke ontbinding, bewijslevering en een switch?, TAP 2015/59.

5 Zie meer uitgebreid: D.M.A. Bij de Vaate, Bijzonder ontslagprocesrecht, Deventer: Kluwer 2015, p. 83-84. 
wetgever ligt het voor de hand dat bij een geschil over een al dan niet terecht verleend ontslag op staande voet het bewijsrecht vol van toepassing zal zijn. ${ }^{6}$

$\mathrm{Al}$ met al valt een beschikking inzake de vernietiging van het ontslag op staande voet niet op korte termijn te verwachten. Dat betekent dat het kort geding onder de Wwz zijn nut en functie behoudt en de werknemer een spoedeisend belang heeft die een voorlopige voorziening rechtvaardigt. Dit neemt niet weg dat ik verwacht dat werknemers onder de Wwz minder snel een kortgedingprocedure zullen starten. Werknemers hebben immers de mogelijkheid in de bodemprocedure die ze verplicht aanhangig moeten maken - een voorlopige voorziening ex artikel 223 van het Wetboek van Burgerlijke Rechtsvordering (Rv) in te stellen. ${ }^{7}$ Via die weg kan de werknemer vooruitlopend op de beschikking inzake vernietiging loon en tewerkstelling vorderen, zonder dat een zelfstandige kortgedingprocedure met alle kosten van dien hoeft te worden opgestart.

\subsection{Samenloopperikelen: non-existente arbeidsovereenkomst}

Dat vernietiging nog slechts in rechte kan, heeft tot gevolg dat de werknemer in kort geding loon en tewerkstelling vordert op een moment dat tussen partijen geen arbeidsovereenkomst bestaat. Het ontbreken van een grondslag staat niet aan het kort geding in de weg. ${ }^{8}$ Een geschil leent zich voor beslechting in kort geding indien de mogelijkheid bestaat een bodemgeschil te starten en er sprake is van een spoedeisend belang. Nadere eisen gelden er niet. Aan deze voorwaarden is bij een ontslag op staande voet voldaan. De werknemer kan een bodemprocedure tot vernietiging starten (artikel 7:681 BW) en is in afwachting van dat oordeel verstoken van inkomsten, hetgeen doorgaans een spoedeisend belang oplevert (zie ook hiervoor). Dat de bodemprocedure (nog) niet aanhangig is, maakt geen verschil. Zolang de mogelijkheid tot een bodemprocedure bestaat - en die bestaat gedurende twee maanden nadat de opzegging heeft plaatsgevonden -, is een kort geding mogelijk.

De plicht tot vernietiging in rechte kan wel leiden tot complicaties. Het gaat in kort geding om het treffen van voorzieningen die gelden voor de tijd dat de juiste rechtsverhouding niet door de rechter in hoofdzaak definitief is vastgesteld. Het kort geding is accessoir aan de bodemprocedure, maar is daarvan niet afhankelijk. Met andere woorden: de bodemprocedure hoeft niet aanhangig te zijn of te zijner tijd aanhangig te worden gemaakt. Het kort geding heeft een zelfstandig karakter. Stel nu dat de werknemer na winst in kort geding verzuimt de bodemprocedure binnen de vervaltermijn aanhangig te maken of een eenmaal gestarte bodemprocedure intrekt. Vernietiging van de opzegging is dan niet meer mogelijk en de arbeidsovereenkomst is rechtsgeldig geëindigd op de datum van het ontslag op

6 Kamerstukken II 2013/14, 33818, 4 (nader rapport van het kabinet), p. 60. Zie ook Kamerstukken I 2013/14, 33818, C, p. 110.

7 HR 5 december 2014, ECLI:NL:HR:2014:3533, m.nt. Van der Kind in TRA 2015/27.

8 Deze problematiek speelde niet onder het oude recht, omdat de werknemer de opzegging buitengerechtelijk kon vernietigen. De arbeidsovereenkomst werd aldus verondersteld te bestaan op het moment dat de werknemer in kort geding loon en tewerkstelling vorderde. Het geschil in de bodemprocedure had betrekking op de vraag of de werknemer de opzegging al dan niet terecht had vernietigd. 
staande voet. Aan de andere kant is de werknemer in het bezit van een executoriaal kortgedingvonnis dat hem recht geeft op loon en tewerkstelling.

Men kan betogen dat de grondslag van het vonnis in kort geding - het bestaan van een arbeidsovereenkomst - is komen te vervallen, zodat de werknemer niet meer tot executie kan overgaan. Deze benadering acht ik niet juist. De Hoge Raad heeft in 1997 geoordeeld dat aan een onherroepelijke uitspraak zonder aanwending van een rechtsmiddel geen rechtskracht kan worden ontzegd, enkel omdat de grondslag waarop de uitspraak berustte is komen te vervallen. ${ }^{9}$ Het ging in deze zaak om de vraag of de werknemer recht had op de in de ontbindingsbeschikking toegekende vergoeding nu de arbeidsovereenkomst voor datum ontbinding was geëindigd door een rechtsgeldig ontslag op staande voet. Hoewel de grondslag voor de ontbindingsbeschikking - het bestaan van een arbeidsovereenkomst - door het ontslag op staande voet was weggevallen, kon de werknemer de in de beschikking toegekende ontbindingsvergoeding executeren. Een ander oordeel zou onverenigbaar zijn met het gesloten systeem van rechtsmiddelen, aldus de Hoge Raad. Hoewel het arrest op een ontbindingsprocedure en niet op een kort geding betrekking had, ligt een analoge toepassing in de rede. Ook het kort geding heeft een zelfstandig karakter.

Uit het arrest kan mijns inziens worden afgeleid dat de rechtskracht van een rechterlijke uitspraak slechts kan worden aangetast via de daartoe beschikbare wettelijke rechtsmiddelen. De rechtskracht van een vonnis in kort geding kan worden aangetast door middel van een vernietiging in hoger beroep, maar ook door middel van een andersluidend oordeel in de bodemprocedure. Laat de werkgever per abuis de hogerberoepstermijn tegen het vonnis in kort geding verstrijken, dan kan hij in een bodemprocedure de kantonrechter verzoeken voor recht te verklaren dat de arbeidsovereenkomst door het ontslag op staande voet rechtsgeldig tot een einde is gekomen. ${ }^{10}$ Kan het eenvoudiger? Ik meen van wel. De kantonrechter in kort geding kan aan een toewijzing van de voorlopige voorziening de voorwaarde verbinden dat de werknemer de bodemprocedure tot vernietiging binnen de vervaltermijn aanhangig maakt en doorloopt. De werkgever moet hiertoe in kort geding wel een vordering in reconventie indienen. De kantonrechter kan deze voorwaarde niet ambtshalve aan de toewijzing van de voorlopige voorziening verbinden.

Tot slot. De situatie is een andere als de werknemer ervoor kiest in de bodemprocedure een voorlopige voorziening ex artikel $223 \mathrm{Rv}$ in te stellen. Anders dan het kort geding hangt de voorlopige voorziening ex artikel $223 \mathrm{Rv}$ samen met de hoofdvordering in de bodemprocedure. Dat betekent dat de bodemprocedure aanhangig moet zijn voordat de werknemer de voorlopige voorziening kan instellen, en de grondslag van een voorlopige voorziening vervalt zodra de werknemer zijn verzoek tot vernietiging intrekt. De samenloopproblematiek die speelt bij het kort geding doet zich daarom niet voor.

9 HR 21 maart 1997, JAR 1997/88 (Stichting Informatica Drenthe Opleidingen).

10 Mocht de werknemer een bodemprocedure zijn gestart, dan kan de werkgever de verklaring voor recht in reconventie vorderen. Dat kan verstandig zijn voor het geval de werknemer zijn verzoek tot vernietiging intrekt. 


\section{De voorwaardelijke ontbindingsprocedure}

\subsection{Bestaansrecht: gerechtvaardigd belang?}

De Hoge Raad heeft de mogelijkheid tot een voorwaardelijke ontbinding na een ontslag op staande voet aanvaard in $1983 .{ }^{11}$ Hoewel het voorwaardelijke ontbindingsverzoek was gegrond op dezelfde feiten en omstandigheden als het ontslag op staande voet, bestond voor de werkgever een gerechtvaardigd belang bij een voorwaardelijke ontbinding van de arbeidsovereenkomst. Het gerechtvaardigd belang was volgens de Hoge Raad gelegen in het feit dat het geruime tijd kon duren voordat over de rechtsgeldigheid van het ontslag op staande voet bij een in kracht van gewijsde gegane uitspraak zekerheid was verkregen. Via de voorwaardelijke ontbinding verkreeg de werkgever zekerheid over het einde van de arbeidsovereenkomst. Het oordeel van de kantonrechter in de ontbindingsprocedure bindt de rechter die oordeelt over het ontslag op staande voet niet. Dat hierdoor tegenstrijdige beslissingen kunnen worden gegeven - ontbindingsrechter ontbindt voorwaardelijk vanwege een dringende reden, terwijl het ontslag op staande voet geen stand houdt -, was volgens de Hoge Raad een onvermijdelijke consequentie van het systeem en hing samen met de afwijkende aard van beide procedures. De Hoge Raad doelde daarmee op het bewijsrecht dat bij de ontbindingsprocedure niet en bij de procedure inzake het ontslag op staande voet wel vol van toepassing is.

Onder het oude recht kreeg de werkgever via de voorwaardelijke ontbinding op korte termijn zekerheid over de risico's van een onterecht gegeven ontslag op staande voet en de daarmee samenhangende potentiële loonvordering van de werknemer. De risico's van een onterecht gegeven ontslag op staande voet bleven beperkt tot het loon vanaf de opzegging tot de ontbindingsdatum, plus een eventuele ontbindingsvergoeding. De snelle zekerheid kwam voort uit het feit dat tegen de ontbindingsbeschikking geen hoger beroep en cassatie openstonden. Dat is sinds 1 juli 2015 anders. Voor de werkgever bestaat onder de Wwz het risico dat het hof hem na een voorwaardelijke ontbinding door de kantonrechter eventueel na verwijzing in cassatie - veroordeelt de arbeidsovereenkomst met terugwerkende kracht te herstellen of aan de werknemer een billijke vergoeding te voldoen (artikel 7:683 lid 6 BW). De voorwaardelijke ontbinding biedt de werkgever daarom niet meer de snelle zekerheid van voorheen. Bovendien moet de werknemer tegenwoordig binnen twee maanden na de opzegging een verzoek tot vernietiging indienen (artikel 7:686a lid 4 onder a sub 2 BW). Dat is een stuk eerder dan voorheen. ${ }^{12}$ Beide wijzigingen roepen de vraag op naar het gerechtvaardigd belang zoals bedoeld door de Hoge Raad in 1983. Heeft de werkgever nog wel een gerechtvaardigd belang bij een voorwaardelijke ontbinding van de arbeidsovereenkomst?

11 HR 21 oktober 1983, NJ 1984/296, m.nt. Stein (Nijman/X). Zie ook HR 3 december 1982, NJ 1983/182 met betrekking tot een ontslag waarin de werknemer volgens de werkgever zou hebben ingestemd.

12 De werknemer had op grond van artikel 9 lid 3 BBA (oud) zes maanden de tijd om de opzegging te vernietigen. 
Bouwens en Bij de Vaate menen van wel. ${ }^{13}$ Verhulp twijfelt. ${ }^{14}$ Ik sluit mij bij de voorstanders aan. Volgens de Hoge Raad bestaat het gerechtvaardigd belang eruit dat de voorwaardelijke ontbinding de arbeidsovereenkomst doet eindigen, terwijl over de rechtsgeldigheid van het ontslag op staande voet geruime tijd onduidelijkheid kan bestaan. Aan dit criterium lijkt mij nog steeds voldaan. Hoewel de werknemer binnen twee maanden na de opzegging de vernietiging daarvan moet verzoeken, kan het geruime tijd duren voordat over de rechtsgeldigheid van het ontslag op staande voet zekerheid is verkregen (zie hiervoor paragraaf 2.1). Ook het openstellen van hoger beroep en cassatie doet niet af aan het gerechtvaardigd belang. Nog steeds zal de ontbindingsprocedure vanwege haar eenvoudige aard eerder tot een in kracht van gewijsde gegane uitspraak leiden dan de procedure inzake het ontslag op staande voet. Bovendien zal het hof in de ontbindingsprocedure vermoedelijk niet snel overgaan tot herstel van de arbeidsovereenkomst (artikel 7:683 lid 3 BW). ${ }^{15}$ Dat betekent dat - ongeacht de mogelijkheid tot hoger beroep en cassatie - de voorwaardelijke ontbinding in eerste aanleg alsnog vaak tot een definitief einde van de arbeidsovereenkomst leidt.

In mijn ogen verzet daarom ook onder de Wwz geen rechtsregel zich tegen het indienen van een voorwaardelijk ontbindingsverzoek na een ontslag op staande voet. De eerste uitspraken na 1 juli 2015 bevestigen deze zienswijze. ${ }^{16}$

\subsection{Samenloopperikelen: technische wijziging procedure ontslag op staande voet}

Dat een gerechtvaardigd belang bestaat, zegt nog niets over het nuttig effect van een verkregen voorwaardelijke ontbinding van de arbeidsovereenkomst. Dat nuttig effect bestaat nog steeds, maar is mijns inziens afgenomen. Dat heeft te maken met een technische verandering in de procedure inzake het ontslag op staande voet. Sinds 1 juli 2015 kan het hof de uitspraak van de kantonrechter inzake de rechtsgeldigheid van het ontslag op staande voet niet meer vernietigen. De wetgever motiveert deze keuze door erop te wijzen dat een vernietiging van de beschikking inzake vernietiging van de opzegging inhoudt dat de opzegging in het verleden herleeft. Dit zou neerkomen op een door het nieuwe stelsel niet beoogde einddatum in het verleden. ${ }^{17}$ Op welk aspect van het nieuwe stelsel de wetgever doelt, wordt niet duidelijk. Ik neem aan dat het gaat om het feit dat onder het nieuwe stelsel hoger beroep en cassatie de tenuitvoerlegging van de beschikking niet schorsen (artikel 7:683 lid 1 BW). De werknemer is aldus na de vernietiging

13 W.H.A.C.M. Bouwens \& D.M.A. Bij de Vaate, 'Voorwaardelijke procedures in het nieuwe ontslagrecht', ARBAC april 2015. Zie ook: Jansen 2015.

14 E. Verhulp, Artikel 7:671b BW, aant. 5, T\&C Arbeidsovereenkomst 2015.

15 Het hoger beroep heeft geen schorsende werking, zodat de ontbinding van de arbeidsovereenkomst tijdens de procedure in stand blijft (artikel 7:683 lid 1 BW). De regering verwacht om die reden dat het hof vermoedelijk niet snel tot herstel zal overgaan, maar dat de rechtsstrijd in hoger beroep met name zal gaan over de hoogte van de billijke vergoeding. Kamerstukken II 2013/14, 33818, 3, p. 35 en 119-120, 4, p. 58 en 7, p. 87.

16 Ktr. Den Haag 27 augustus 2015, JAR 2015/231, m.nt. Helstone; Ktr. Noord-Holland 30 juli 2015, JAR 2015/217; Ktr. Rotterdam 28 september 2015, ECLI:NL:RBROT:2015:6923; Ktr. Assen 15 september 2015, ECLI:NL:RBNNE:2015:4342.

17 Kamerstukken II 2013/14, 331818, 3, p. 120. 
van de opzegging in eerste aanleg weer aan het werk geweest op basis van een arbeidsovereenkomst.

Wat de reden ook is geweest, de technische wijziging heeft consequenties voor een toegekende voorwaardelijke ontbinding van de arbeidsovereenkomst. Allereerst het voorbeeld dat de wetgever noemt in de hiervoor aangehaalde parlementaire geschiedenis. De werkgever verliest de procedure inzake het ontslag op staande voet in eerste aanleg en wint in hoger beroep. Voorheen eindigde de arbeidsovereenkomst op de datum van het ontslag op staande voet en herleefde de opzegging in het verleden. Onder de Wwz kan het hof de arbeidsovereenkomst nog slechts laten eindigen tegen een datum in de toekomst (artikel 7:683 lid 6 BW). ${ }^{18}$ Dit betekent dat de arbeidsovereenkomst nog bestaat op de datum waartegen voorwaardelijk is ontbonden en de arbeidsovereenkomst eindigt door ontbinding. Heeft de kantonrechter in de ontbindingsbeschikking aan de werknemer een transitievergoeding en eventueel een billijke vergoeding toegekend, ${ }^{19}$ dan is de werkgever gehouden deze bedragen aan de werknemer te voldoen.

Deze uitkomst bevreemdt. Het hof heeft immers de werkgever in het gelijk gesteld en het ontslag op staande voet rechtsgeldig geacht. Ik meen dat het hof niet in zijn beschikking inzake het ontslag op staande voet kan opnemen dat de werkgever de in de voorwaardelijke ontbindingsbeschikking opgenomen bedragen niet hoeft uit te keren. Dan wordt immers aan een onherroepelijke uitspraak zonder aanwending van een rechtsmiddel rechtskracht ontzegd en dat is in strijd met het gesloten stelsel van rechtsmiddelen. ${ }^{20}$ De werkgever is daarnaast loon verschuldigd over de periode tot aan de ontbindingsdatum. Het hof lijkt evenmin de mogelijkheid te hebben de loonvordering te matigen op grond van artikel 7:680a BW. De loonvordering heeft betrekking op de periode gelegen tussen de opzegging en de ontbinding en is aldus niet gebaseerd op de vernietiging van de opzegging.

Dan de spiegelbeeldige situatie: de werkgever wint de procedure inzake het ontslag op staande voet in eerste aanleg en verliest in hoger beroep. Voorheen had de uitspraak van het hof tot gevolg dat de arbeidsovereenkomst was blijven bestaan en eindigde door de voorwaardelijke ontbinding. Onder de Wwz kan het hof op verzoek van de werknemer de werkgever veroordelen de arbeidsovereenkomst te herstellen. Het hof is vrij in het bepalen van de ingangsdatum (artikel 7:683 lid 3 BW). De datum kan liggen na de datum waartegen de voorwaardelijke ontbinding is uitgesproken. De werkgever heeft in dat geval niets aan de voorwaardelijke ontbinding van de arbeidsovereenkomst. Maar ook als het hof de ingangsdatum bepaalt voor het moment dat de voorwaardelijke ontbinding is uitgesproken, verwacht ik dat de werkgever met lege handen staat. De herstelde arbeidsovereen-

18 Kamerstukken II 2013/14, 33818, 3, p. 120.

19 Een transitievergoeding is niet verschuldigd bij ernstig verwijtbaar handelen aan de kant van de werknemer (artikel 7:673 lid 7 onder c BW). Een billijke vergoeding is mogelijk indien de kantonrechter oordeelt dat de grondslag voor de voorwaardelijke ontbinding te wijten is aan ernstig verwijtbaar handelen van de werkgever (artikel 7:671b lid 8 onder c BW).

20 Dat volgt uit het in paragraaf 2.2 genoemde arrest van de Hoge Raad van 21 maart 1997, JAR 1997/88 (Stichting Informatica Drenthe Opleidingen). 
komst heeft naar mijn mening te gelden als een nieuwe arbeidsovereenkomst, zodat de voorwaardelijke ontbindingsbeschikking daarop geen betrekking heeft. ${ }^{21}$ Kortom: zodra met succes tegen de beschikking van de kantonrechter inzake de procedure van het ontslag op staande voet hoger beroep wordt ingesteld, heeft de werkgever bij een voorwaardelijke ontbinding van de arbeidsovereenkomst geen belang meer. Sterker nog, in de situatie dat de werkgever na verlies in eerste aanleg wint in hoger beroep, brengt de voorwaardelijke ontbindingsbeschikking zelfs financiële risico's voor hem mee.

\section{Een persoonlijke noot ter afsluiting}

Vanaf het eerste moment dat ik vijf jaar geleden als redactiesecretaris tot de redactie van ArA toetrad, heb ik mij welkom gevoeld. Cees Loonstra zorgde als officieuze voorzitter tijdens de redactievergaderingen voor een open atmosfeer waarin ik mij als beginnend wetenschapper vrij voelde mee te doen aan de discussies. Alle redactieleden waren aan elkaar gelijk; er bestond geen onderscheid tussen hoogleraar of promovendus. Ook Corjo Jansen droeg bij aan deze prettige sfeer en had als meer algemeen civilist en rechtshistoricus een voor mij verfrissende kijk op het arbeidsrecht. Ik heb de afgelopen jaren als redactiesecretaris veel geleerd op juridisch maar ook op persoonlijk vlak. Ik dank beide heren voor de gezellige samenwerking en Cees in het bijzonder voor zijn waardevolle adviezen tijdens onze regelmatige etentjes na afloop van de vergaderingen. Corjo Jansen zal ik de komende jaren zeker nog tegenkomen in de gangen van de Nijmeegse faculteit. Dat geldt niet voor Cees Loonstra. Toch heb ik ook bij Cees het gevoel dat we elkaar niet uit het oog zullen verliezen.

21 Dit risico zal zich naar mijn verwachting in de praktijk niet vaak verwezenlijken. Artikel 7:683 lid 3 BW biedt het hof ambtshalve de mogelijkheid aan de werknemer een billijke vergoeding toe te kennen als alternatief voor herstel. Gezien het tijdsverloop en verschillende procedures die spelen na een ontslag op staande voet zal het hof waarschijnlijk vaak kiezen voor een billijke vergoeding in plaats van herstel (zie ook Kamerstukken II 2013/14, 33818, 3, p. 35). Hiervan uitgaande zal het oordeel van de kantonrechter dat het ontslag op staande voet standhoudt, leiden tot een definitief einde van de arbeidsovereenkomst. Feit blijft dat ook in deze situatie de voorwaardelijke ontbinding niets toevoegt. De arbeidsovereenkomst eindigt immers door het ontslag op staande voet. 